\title{
Alloying and Phase Transformation of Fe/FeNi Core/Alloy Nanoparticles at High Temperatures
}

\author{
Tennyson L. Doane ${ }^{\#}$, Laxmikant Pathade, R. Davon Slaton, \\ Michael E. Klaczko, Mathew M. Maye* \\ Department of Chemistry, Syracuse University, Syracuse, New York, 13244 \\ \#Current Address: Department of Chemistry, Eastern Nazarene College, Quincy, MA, 02170 \\ *mmmaye@syr.edu
}

\begin{abstract}
This work explores how to form and tailor the alloy composition of $\mathrm{Fe} / \mathrm{Fe}_{\mathrm{x}} \mathrm{Ni}_{1-\mathrm{x}}$ core/alloy nanoparticles by annealing a pre-formed particle at elevated temperatures between $180-325{ }^{\circ} \mathrm{C}$. This annealing allowed for a systematic FeNi alloying at a nanoparticle whose compositions and structure began as a $\alpha$-Fe rich core, and a thin $\gamma$-Ni rich shell, into mixed phases resembling $\gamma$ $\mathrm{FeNi}_{3}$ and $\gamma-\mathrm{Fe}_{3} \mathrm{Ni}_{2}$. This was possible in part by controlling surface diffusion via annealing temperature, and the enhanced diffusion at the many grain boundaries of the nanoparticle. Lattice expansion and phase change was characterized by powder X-ray diffraction (XRD), and composition was monitored by X-ray photoelectron spectroscopy (XPS). Of interest is that no phase precipitation was observed (i.e., heterostructure formation) in this system and the XRD results suggest that alloying composition or alloy gradient is uniform. This uniform alloying was considered using calculations of bulk diffusion and grain boundary diffusion for $\mathrm{Fe}$ and Ni selfdiffusion, as well as Fe-Ni impurity diffusion is provided. In addition, alloying was further considered by calculations for Fe-Ni mixing enthalpy $\left(\Delta \mathrm{H}_{\text {mix }}\right)$ and phase segregation enthalpy $\left(\Delta \mathrm{H}_{\mathrm{Seg}}\right)$ using the Miedema model, which allowed for the consideration of alloying favorability or core-shell segregation in the alloying, respectively. Of particular interest is the formation of stable metal carbides compositions, which suggest that the typically inert organic self-assembled monolayer encapsulation can also be internalized.
\end{abstract}

Keywords: Core/Alloy, FeNi, Nanoparticle, Alloying, Stainless 


\section{INTRODUCTION}

The ability to use synthetic inorganic nanochemistry ${ }^{1}$ to fabricate nanoparticles resembling steels $^{2}$ from a purely wet chemical approach would allow for the development of nanometer-thin metal, magnetic, and stainless coatings, as well as new classes of lubricants and additive manufacturing ingredients. Iron-nickel (FeNi) alloys, possess stainless behavior while retaining high magnetization and strength, which has led to broad applications ranging from telecommunications to turbines, and heat exchangers to industrial coatings. ${ }^{3}$ One FeNi alloy is Invar steel, which has a nominal composition of $\mathrm{Fe}_{0.64} \mathrm{Ni}_{0.36}$, and is important in electronics and precision engineering due to its negligible thermal expansion, ${ }^{4}$ as well as novel electromagnetic properties. $^{3}$ FeNi metallic alloys have also been tested at the nanoscale, showing high magnetization ${ }^{5}$ and tunable compositions, ${ }^{6}$ including that of Invar. ${ }^{7,8}$ These materials are also useful in radiation absorbers,,${ }^{9,10}$ catalysis, ${ }^{1112,13}$ imaging $^{14}$ and sensors. ${ }^{15}$

A number of nanostructured FeNi alloys have also been prepared or studied at the nanoscale. ${ }^{12,16-23}$ The different synthetic strategies and potential applications often overshadow the difficulty in understanding and predicting the alloying of FeNi at the nanoscale, where enhanced diffusion, ${ }^{24}$ and improved mixing enthalpies ${ }^{25-27}$ are contrasted with a higher contribution of surface energies and interfacial strain. ${ }^{28}$ Taken together, it is still challenging to model and describe equilibrium alloy nano-structures. ${ }^{29,30}$ The refinement of a number of models, however, is aided by the growing accumulation of experimental data related to the composition and microstructure changes of alloy NPs as a function of time and temperature. ${ }^{30,31}$ 
We have been developed a core/alloy (CA) approach towards crafting alloy nanoparticle interfaces. ${ }^{2,32-34}$ By focusing on depositing or forming a nanometer thin alloy at a pre-formed nanoparticle interface, we attempt to overcome challenges often faced when mixing metal salts followed by co-reduction, ${ }^{6,35-37}$ electrochemical reduction, ${ }^{38,39}$ performing galvanic displacement, ${ }^{34}$ or thermal treatment, ${ }^{40,41}$ where differences in redox potentials, decompositions, and precursor reactivity makes controlling the final alloy composition, distribution, and phase homogeneity, difficult.

A key to this approach is the slow sequential deposition of sub-monolayer to monolayer thicknesses of a solute metal, originating from an organometallic precursor (i.e., metal carbonyls), at a crystalline pre-formed nanoparticle. This allows for metallic alloying to occur, instead of rapid galvanic exchange between the solute precursor and the nanoparticle. Previous core/alloy studies have focused on substantiating the approach and implementing different metal combinations and annealing at modest temperatures of $100-180^{\circ} \mathrm{C}$. In this work we expand understanding of the core-alloy approach using a $\mathrm{Fe} / \mathrm{Fe}_{1-\mathrm{x}} \mathrm{Ni}_{\mathrm{x}}$ nanoparticle by first considering the influence of thermodynamics and diffusion kinetics at the core-alloy interface. We then experimentally validate the approach by studying the alloying and phase change during elevated temperature annealing using X-ray diffraction (XRD). 


\section{Experimental}

Materials: Iron (0) pentacarbonyl ( $\left.\mathrm{Fe}(\mathrm{CO})_{5}, 99.5 \%\right)$, (bistriphenyphosphine)dicarbonyl nickel (0) $\left(\mathrm{Ni}\left(\mathrm{PPh}_{3}\right)_{2}(\mathrm{CO})_{2}, 98 \%\right.$ anhydrous), oleylamine (OAm, 70\%), 1-octadecene (ODE, 90\%), dioctylether (DOE, 99\%), hexadecylamine (HDA, 98\%), hydrochloric acid ( $\mathrm{HCl}, 1.0 \mathrm{M}$ in diethylether), and ethanol (EtOH, 200 proof) were purchased from Sigma-Aldrich and used without further purification.

Core/Alloy Nanoparticle Synthesis \& Annealing: Crystalline $\alpha$-Fe nanoparticles were prepared according to a previous method. ${ }^{42,43}$ In a typical $\alpha$-Fe synthesis, $15.0 \mathrm{~mL}$ of ODE, $100.0 \mathrm{mg}$ $\mathrm{HDACl}$, and $0.5 \mathrm{~mL}$ of $\mathrm{OAm}$ was combined and degassed at $120^{\circ} \mathrm{C}$ for $0.5 \mathrm{~h}$. This mixture was then heated to $180{ }^{\circ} \mathrm{C}$ in a four neck flask under $\mathrm{Ar}$, and $0.2 \mathrm{~mL}$ of $\mathrm{Fe}(\mathrm{CO})_{5}$ was injected under $\mathrm{Ar}$. The solution was agitated through shaking and Ar bubbling to avoid collection of the NPs on a magnetic stir-bar. After annealing for $0.5 \mathrm{~h}$ at $180{ }^{\circ} \mathrm{C}, \sim 5 \mathrm{~mL}$ of the reaction volume was removed, cooled to room temperature, and then precipitated with dry EtOH for analysis. The un-cleaned $\alpha$ Fe aliquots were kept in the reaction vessel under Ar gas and used as the core for nickel deposition, as described next. Next, nickel was deposited at the $\alpha$-Fe NP cores. During shell deposition, $5 \mathrm{~mL}$ solution of $\mathrm{Ni}\left(\mathrm{PPh}_{3}\right)_{2}(\mathrm{CO})_{2}(0.5 \mathrm{M}$ in THF) was injected into the remaining solution of $\alpha$-Fe cores synthesized above. Total volume of $\mathrm{Ni}\left(\mathrm{PPh}_{3}\right)_{2}(\mathrm{CO})_{2} / \mathrm{THF}$ solution was split into ten separate injections $(0.5 \mathrm{~mL}$ each $)$ to maintain steady annealing temperature, with 15 minutes of annealing time between injections. After completing Ni precursor injections, the reaction was let to cool to room temperature. The NPs were purified by precipitation in dry EtOH (200 proof) under Ar. After centrifugation (10 min, $4400 \mathrm{RPM}$ ), the product was re-dispersed in dry hexane and stored under Ar. During these experiments NP samples were annealed in a small round bottom flask at a given temperature for 5 hours. Annealing took place under Ar flow and precautions were taken to limit 
$\mathrm{O}_{2}$ exposure. $0.5 \mathrm{~mL}$ of stock $\mathrm{Fe} / \mathrm{Ni}$ core shell $\mathrm{NPs}(\approx 720 \mathrm{mg})$ were added to $5 \mathrm{~mL}$ ODE under inert conditions. To prevent aggregation, $0.1 \mathrm{~mL}$ of oleylamine was added as well. The temperature was raised to the target temperature and the solution was allowed to anneal for 5 hours. The solution was then cooled and precipitated in dry ethanol using the previously described cleaning procedure, and subsequent analysis was conducted.

Instrumentation: TEM imaging was performed at the Upstate Medical University, Syracuse, NY using a JEOL 2000 transmission electron microscope operated at $200 \mathrm{kV}$, equipped with a $\mathrm{LaB}_{6}$ filament and TVIPS 4K CCD camera. Samples were drop cast onto a 300-mesh ultra thin type A carbon copper grid (Ted Pella). Powder X-ray diffraction (XRD) patterns were taken on a Bruker D8 Advance powder diffractometer that utilized Cu-K $\mathrm{K}_{\alpha} \mathrm{X}$-rays $(\lambda=1.5406 \AA)$. Samples were dried and loaded on a zero-diffraction $\mathrm{SiO}_{2}$ crystal (MTI Corp.). The reference data were obtained from the PDF-4+ database (ICCD) for phase identification and comparison. The corresponding lattice constants were calculated using Bragg's law, $2 d \sin \theta=n \lambda \quad$ where $\theta$ is the diffraction angle, $n$ is an integer taken as unity, $\lambda$ is the x-ray wavelength, and $d$ is related to the Miller indices of the FCC lattice by $d=a\left(h^{2}+k^{2}+l^{2}\right)^{-1 / 2}$. Similarly, the grain size $(\tau)$ was estimated using the Scherrer equation given by: $\tau=\frac{K \lambda}{\beta \cos \theta} \quad$ where $K$ is a dimensionless factor taken near unity ( 0.9 for near spherical objects), $\beta$ is the peak broadening (full width half maximum) in radians, and $\theta$ is the diffraction angle in radians. The Fityk software package ${ }^{44}$ was used to confirm the lattice constants obtained from the $<111>$ indice peak reflections in Figure 4 and for the analysis of the lower intensity $\langle 200\rangle$ and $\langle 220\rangle$ reflections (shown in Figure S3), revealing that the actual composition is likely $8-10 \%$ lower than that calculated from the $<111>$ reflection. 


\section{RESULTS AND DISCUSSION}

In this section we first describe the experimental system and characterization of alloying for the model iron-nickel core-alloy nanoparticle, denoted for simplicity as $\mathrm{Fe} / \mathrm{Fe}_{1-\mathrm{x}} \mathrm{Ni}_{\mathrm{x}}$. We then investigate the phase behavior as well as the kinetic and thermodynamic factors governing alloying at the interface.

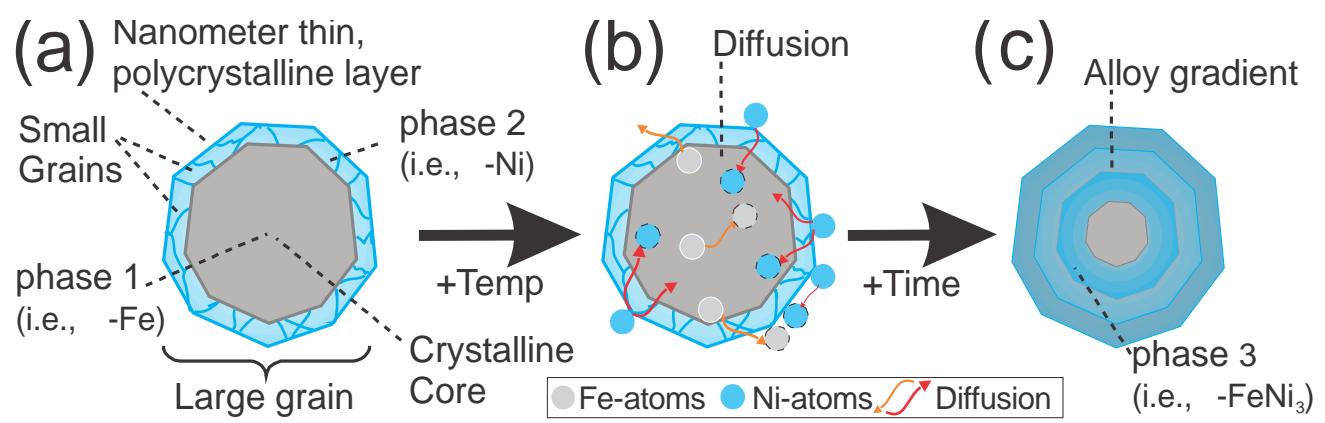

Scheme 1: An idealized illustration of the $\mathrm{Fe} / \mathrm{Fe}_{1-\mathrm{x}} \mathrm{Ni}_{\mathrm{x}}$ core/alloy system. A pre-synthesized metallic $\mathrm{Fe} / \mathrm{Fe}_{1-\mathrm{x}} \mathrm{Ni}_{\mathrm{x}} \mathrm{NP}$ with an $\alpha$-Fe rich core, and a $\gamma$-Ni rich shell (a) is annealed at high temperatures which induce alloying at the interface and multiple grain boundaries (b), resulting in a new $\mathrm{Fe} / \mathrm{Fe}_{1-\mathrm{x}} \mathrm{Ni}_{\mathrm{x}} \mathrm{NP}$ that has a more homogeneous alloy gradient and a new alloy phase, such as $\gamma-\mathrm{FeNi}_{3}$. For simplicity, the monolayer coatings of $\mathrm{OAm}, \mathrm{OAc}$, and $\mathrm{HDACl}$ are not shown here.

Scheme 1 shows an idealized illustration of the model $\mathrm{Fe} / \mathrm{Fe}_{1-\mathrm{x}} \mathrm{Ni}_{\mathrm{x}}$ system studied. A crystalline metal nanoparticle $(\alpha-\mathrm{Fe})$ was used as a seed in which a nanometer thin nickel $(\mathrm{Ni})$ shell was deposited (a). Depending on the shell layer thickness, the interface can adopt the underlying core structure (i.e., b.c.c. $(\alpha)$ at low thickness), or adopt a new one (i.e., f.c.c. $(\gamma)$ at high thickness), and in both cases the shell is considered to be more polycrystalline than the core. This is important, as these polycrystalline 'grains', and the larger core 'grain' are considered later and hypothesized to aid alloying. Annealing at elevated temperatures for prolonged periods of time (1b), produces new alloy phases, gradients of phases, or gradients of concentrations (1c). 

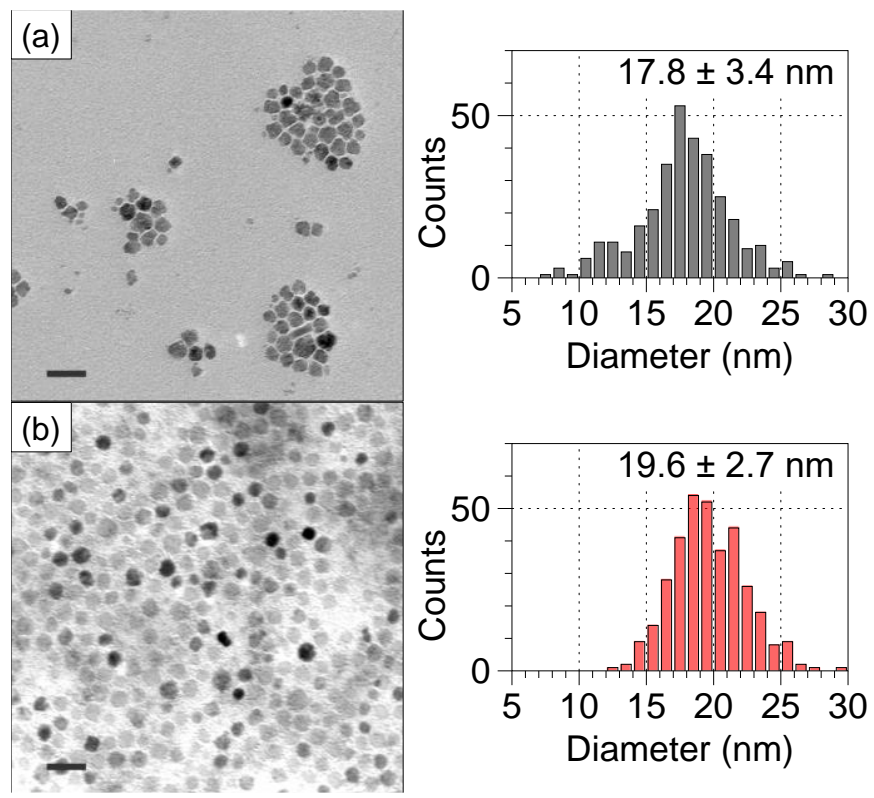

Figure 1. Representative TEM micrographs for Fe core NPs (a) and Fe/Ni core/alloy NPs synthesized at $180{ }^{\circ} \mathrm{C}(\mathrm{b})$, with corresponding size histograms (scale bar $=50 \mathrm{~nm}$ ).

The $\mathrm{Fe} / \mathrm{Fe}_{\mathrm{x}} \mathrm{Ni}_{1-\mathrm{x}} \mathrm{NPs}$ were synthesized by preparing a crystalline $\alpha-\mathrm{Fe} \mathrm{NPs},{ }^{42,43}$ capped with a mixture of oleylamine (OAm) and hexadecylammonium chloride (HDACl) ligands. This was followed by the deposition of a thin layer of metallic $\mathrm{Ni}$ onto the $\alpha$-Fe by the thermal decomposition of the organometallic precursor $\mathrm{Ni}(\mathrm{CO})_{2}\left(\mathrm{PPh}_{3}\right)_{2}$ at $180{ }^{\circ} \mathrm{C} .{ }^{32} \mathrm{~A}$ thin $\mathrm{Ni}$ layer was deposited by controlling the $[\alpha-\mathrm{Fe}]:\left[\mathrm{Ni}(\mathrm{CO})_{2}\left(\mathrm{PPh}_{3}\right)_{2}\right]$ feed ratios, after considerations to NP concentration and desired shell volumes. Figure 1 shows representative Transmission Electron Microscopy (TEM) results for the $\alpha-\mathrm{Fe}$ (a) which had a diameter of $d_{F e} \approx 17.7$, and the $\mathrm{Fe} / \mathrm{Fe} \mathrm{x}_{\mathrm{x}} \mathrm{Ni}_{1}$ x with $d_{F e N i} \approx 19.6 \mathrm{~nm}$. After the initial decomposition of $\mathrm{Ni}^{0}$ from $\mathrm{Ni}(\mathrm{CO})_{2}\left(\mathrm{PPh}_{3}\right)_{2}$ was complete, the samples were purified free of excess OAm, OAc, or HDACl ligands, before being redispersed in ODE and OAm and annealed at temperatures of 250,315 and $325^{\circ} \mathrm{C}$ for $5 \mathrm{~h}$, followed by standard purification. 


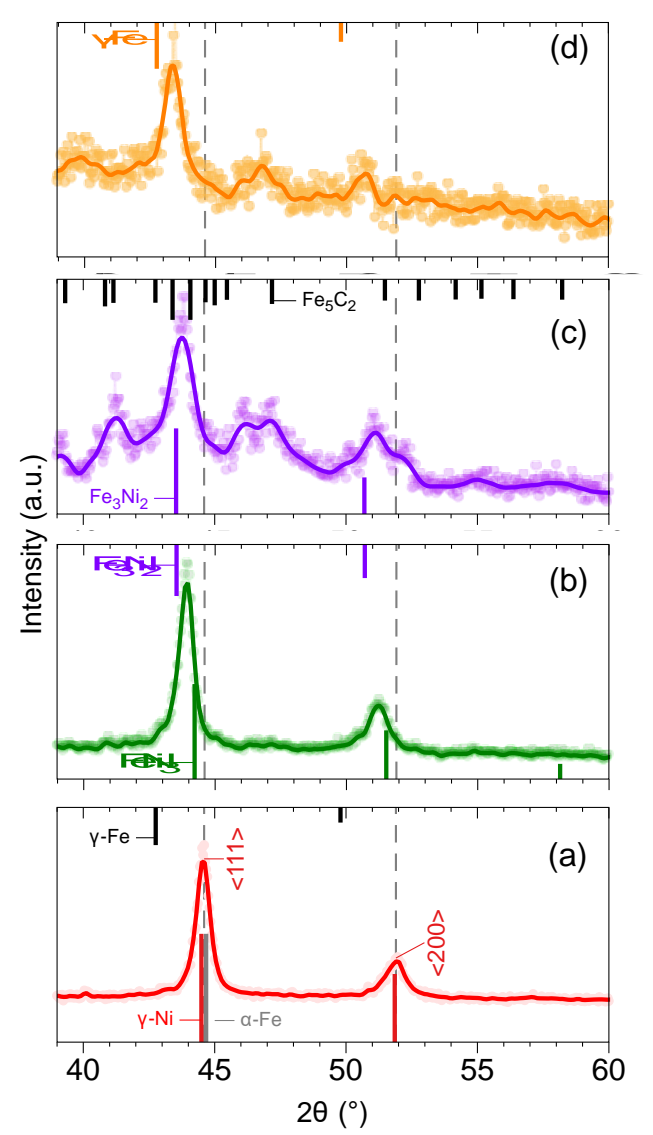

Figure 2. Representative $\mathrm{XRD}$ of $\mathrm{Fe} / \mathrm{Fe}_{1-\mathrm{x}} \mathrm{Ni}_{\mathrm{x}} \mathrm{NPs}$ synthesized at $180{ }^{\circ} \mathrm{C}(\mathrm{a})$, and after annealing for $5 \mathrm{~h}$ at 250 (b), 315 (c), and $325{ }^{\circ} \mathrm{C}$ (d), with corresponding references bulk $\alpha$-Fe (b.c.c.), $\gamma-\mathrm{Ni}$ (f.c.c.), $\mathrm{FeNi}_{3}, \mathrm{Fe}_{3} \mathrm{Ni}_{2}, \mathrm{Fe}_{5} \mathrm{C}_{2}$, and $\gamma$ - $\mathrm{Fe}$ (f.c.c.).

To observe alloying and phase transformations during annealing, characterization by powder X-ray diffraction (XRD) was performed. Figure 3a shows a set of representative powder $\mathrm{XRD}$ results for the $\mathrm{Fe} / \mathrm{Fe}_{\mathrm{x}} \mathrm{Ni}_{1-\mathrm{x}}$ as synthesized at $180{ }^{\circ} \mathrm{C}$ (a) and after annealing at 250 (b) and 315 (c), and $325{ }^{\circ} \mathrm{C}(\mathrm{d})$. For example, the as-synthesized $\mathrm{Fe} / \mathrm{Fe}_{\mathrm{x}} \mathrm{Ni}_{1-\mathrm{x}}$ shows two key characteristics. First, the primary reflection at $\sim 44^{\circ}$ is indicative of both the $\alpha$-Fe (b.c.c.) structure $\left(2 \theta_{<110>}=\right.$ $\left.44.6^{\circ}\right)$ as well as $\gamma$-Ni (f.c.c.) $\left(2 \theta<111>=44.4^{\circ}\right)$, but the strong $<200>$ at $2 \theta=51.9$ and $\left.<220\right\rangle$ at $75.6^{\circ}$ (not shown), is indicative of a highly crystalline Ni shell or crystalline $\gamma$-FeNi alloy (see below). Upon annealing at $250{ }^{\circ} \mathrm{C}$ (ii), there are pronounced shifts in the $\langle 111\rangle$, $\langle 200\rangle$, and $<220>$ reflections to lower $2 \theta$, indicating an increasing Ni content in the growing FeNi alloy phase. 
This trend continues at annealing of 315 (c) and $325{ }^{\circ} \mathrm{C}$ (d). The reference indices for $\gamma-\mathrm{Fe}, \mathrm{FeNi}_{3}$, $\mathrm{Fe}_{3} \mathrm{Ni}_{2}$ are shown for comparison. For instance, at $315-325^{\circ} \mathrm{C}$ the $\mathrm{Fe} / \mathrm{Fe}_{\mathrm{x}} \mathrm{Ni}_{1-\mathrm{x}}$ has a strong $\mathrm{Fe}_{3} \mathrm{Ni}_{2}$ character. In addition, at these temperatures we also observed broadening and new reflections which do not index well with either alloys or oxides. For instance, the reference reflection for iron carbides, such $\gamma-\mathrm{Fe}_{5} \mathrm{C}_{2}$. This alloying trend was reproduced multiple times, with similar results observed for a $\mathrm{Fe} / \mathrm{Fe}_{\mathrm{x}} \mathrm{Ni}_{1-\mathrm{x}}$ with a thinner $\mathrm{Ni}$-shell and more b.c.c. like starting point, as show in Figure S3.

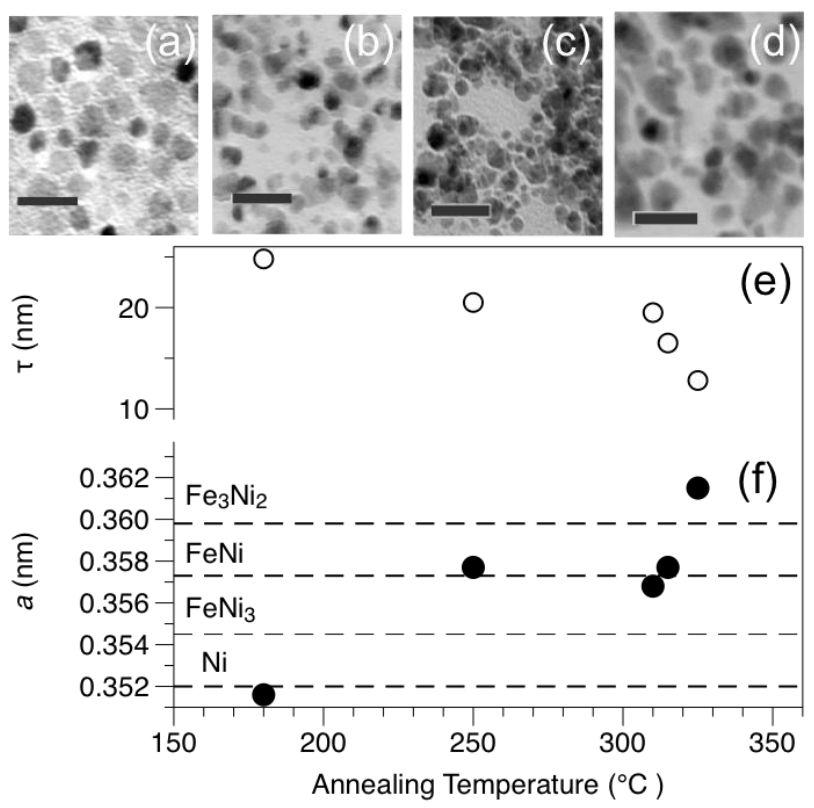

Figure 3. Representative TEM micrographs of the as synthesized $\mathrm{Fe} / \mathrm{Fe}_{1-\mathrm{x}} \mathrm{Ni}_{\mathrm{x}} \mathrm{NP}$ (a), and those annealed at 250 (b), 315 (c), and $325^{\circ} \mathrm{C}$ (d) for 5h. Analysis of XRD results showing Scherrer determined grain sizes (e) and calculated lattice constants (f) with bulk FeNi alloy positions.

Figure 3 shows a set of TEM results of the synthesized $\mathrm{Fe} / \mathrm{Fe}_{\mathrm{x}} \mathrm{Ni}_{1-\mathrm{x}}$ at $180{ }^{\circ} \mathrm{C}(\mathrm{a})$, and after annealing at 250 (b), 315 (c), and $325^{\circ} \mathrm{C}$ (d). Some changes in distribution and morphology is observed in these low resolution micrographs. Figure $3 \mathrm{e}$ plots approximate grain size $(\tau)$ determined from Scherrer analysis of the primary reflection in the XRD from Figure 2 (i.e., <111>), while Figure 3f shows calculated lattice constant (a) of the reflection. We observe a decreasing 
trend in $\tau$ with increasing annealing time, which is consistent with the TEM results for this series of experiments (Fig. 3a-d), and a increasing trend in $a$, which corresponds closely with the increasingly Ni-rich alloys.
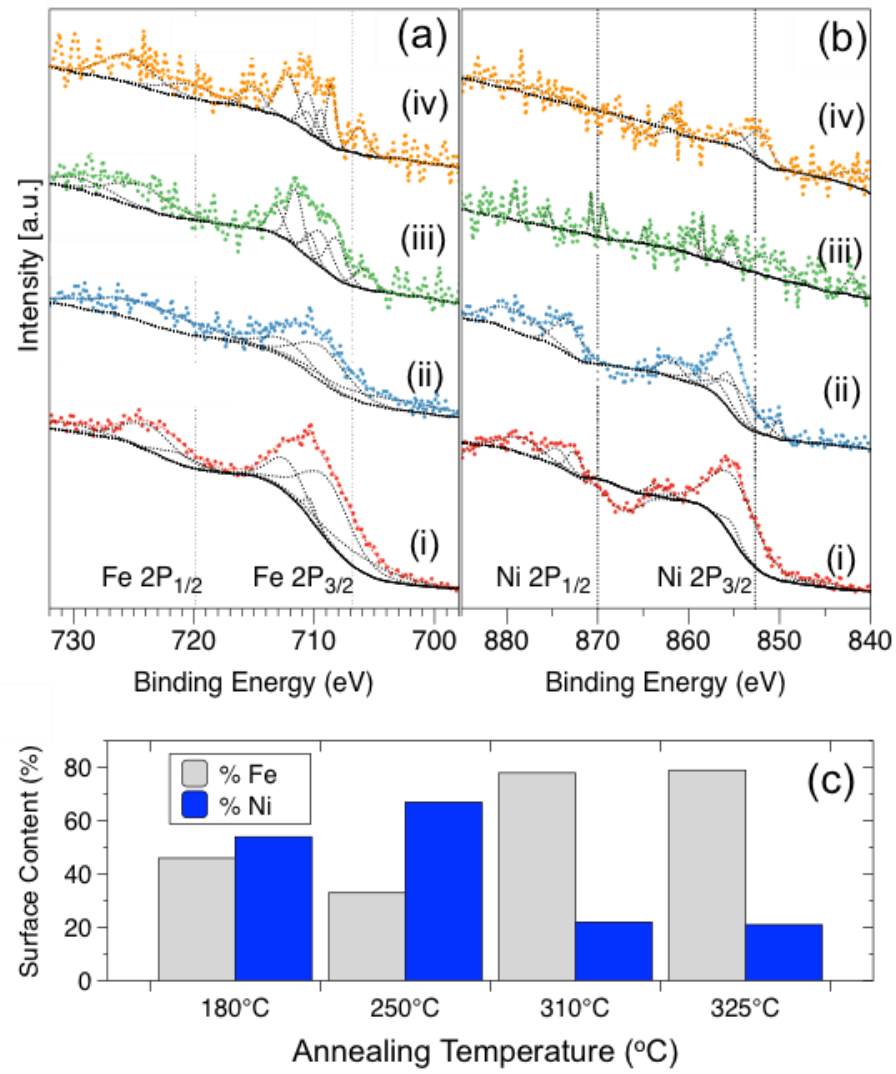

Figure 4. Representative XPS results for the Fe $2 p$ (a) and $\mathrm{Ni} 2 \mathrm{p}$ (b) binding energy regions for the $\mathrm{Fe} / \mathrm{Fe}_{1-\mathrm{x}} \mathrm{Ni}_{\mathrm{x}} \mathrm{NP}$ synthesized at $180{ }^{\circ} \mathrm{C}$ (i), and those annealed at 250 (ii), 310 (iii), and $325{ }^{\circ} \mathrm{C}$ (iv) for $5 \mathrm{~h}$, as well as a summary of XPS determined composition ratios (c).

To further probe the change in alloy composition at the interface of these particles, X-ray photoelectron spectroscopy (XPS) was utilized. Figure 4 shows the Fe $2 p$ (a) and Ni 2p (b) binding energy (B.E.) regions for the initial $\mathrm{Fe} / \mathrm{Fe}_{1-\mathrm{x}} \mathrm{Ni}_{\mathrm{x}} \mathrm{NP}$ synthesized at $180{ }^{\circ} \mathrm{C}$ (i). Both $\mathrm{Fe}$ and $\mathrm{Ni}$ signatures are clearly present, and analysis of the composition ratio is shown in Figure 4c, which reveals an approximate composition of $\mathrm{Fe}: \mathrm{Ni}$ of 45:55, which is consistent with a thin Ni-shell at the interface of the NP, considering the penetration depth of XPS analysis. Interestingly, analysis 
of the samples annealed at higher temperatures, as shown above in XRD and TEM, reveal higher Fe:Ni ratios, which is consistent with the proposed alloying, where Fe from the core diffuses towards the interface, and Ni diffuses within the NP.

One unique aspect of these results is the relative ease of which alloy composition can be tuned and that no observable phase segregation occurred. To better understand this, consider the FeNi binary phase diagram shown in Figure 5a, which is reproduced with modification from bulk FeNi tables. ${ }^{45}$ If we consider a constant temperature of $\sim 200{ }^{\circ} \mathrm{C}$ and increasing Ni concentration, then mixed phases of $\alpha-\mathrm{Fe}$ and $\mathrm{FeNi}_{3}$ are expected, and similarly mixtures of $\alpha-\mathrm{Fe}$ and $\gamma-\mathrm{Fe}_{\mathrm{x}} \mathrm{Ni}_{\mathrm{y}}$ are expected at temperatures greater than $\sim 350{ }^{\circ} \mathrm{C}$. Considering that mixed phases were not observed at the annealing temperatures of $180-325^{\circ} \mathrm{C}$ in this study suggests that the nano FeNi phase diagram is suppressed and that a multitude of $\gamma-\mathrm{Fe}_{\mathrm{x}} \mathrm{Ni}_{\mathrm{y}}$ phases are possible using this approach. This finding is in agreement with other studies that studied nanoscale phase diagrams. ${ }^{46}$ 

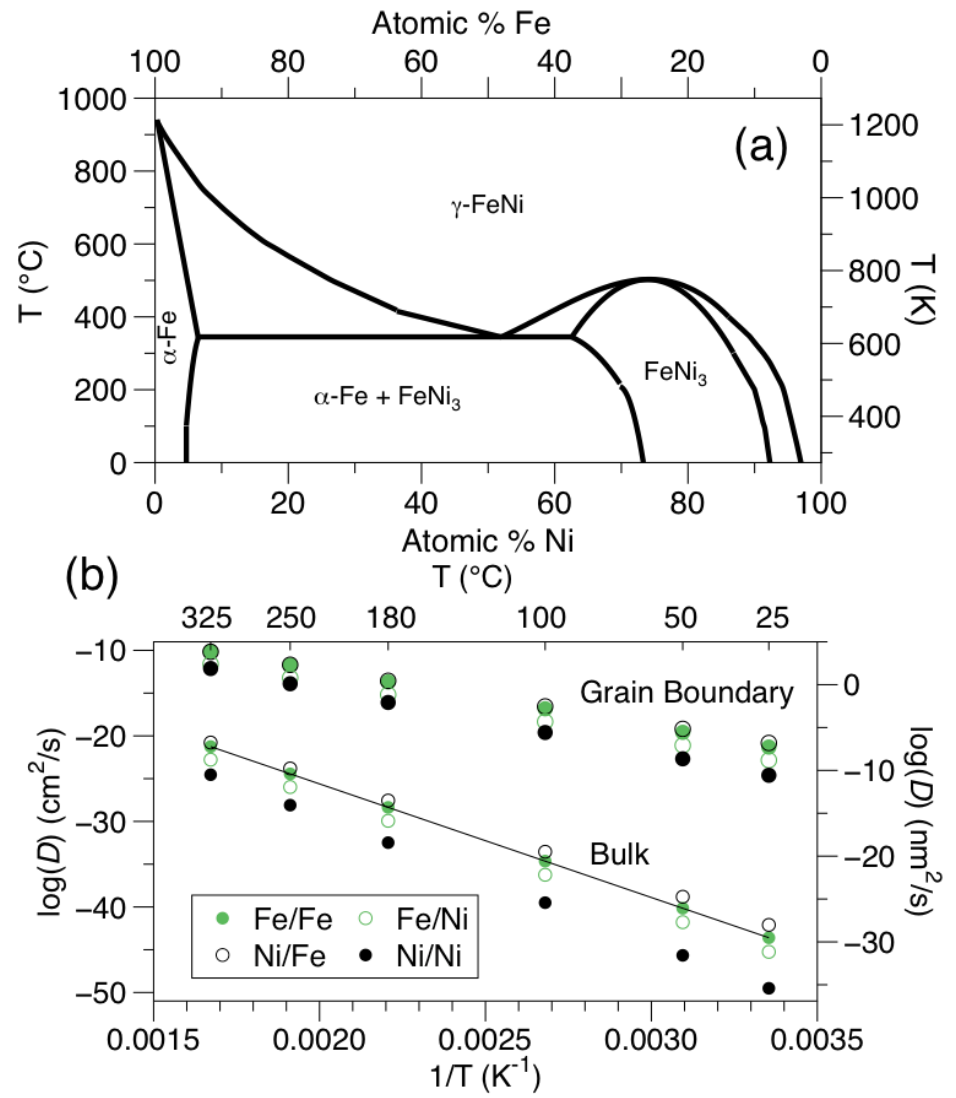

Figure 5. (a) An illustration of the phase diagram for binary FeNi alloys (adapted from reference $\left.^{45}\right)$. (b) Plots of the calculated diffusion coefficients for the bulk $\left(D_{\mathrm{B}}\right)$ (lower) and grain boundary $\left(D_{\mathrm{gb}}\right)$ (upper) diffusion of $\mathrm{Fe}$ in $\mathrm{Fe}(\mathrm{Fe} / \mathrm{Fe}), \mathrm{Ni}$ in $\mathrm{Fe}(\mathrm{Ni} / \mathrm{Fe}), \mathrm{Ni}$ in $\mathrm{Ni}(\mathrm{Ni} / \mathrm{Ni})$, and $\mathrm{Fe}$ in $\mathrm{Ni}(\mathrm{Fe} / \mathrm{Ni})$ as a function of temperature. See SI for more information.

One potential reason for this suppression in the phase behavior is the more rapid diffusion at nano interfaces compared to bulk. Such diffusion is approximated using Fick's law and transition-state theory, ${ }^{24,47}$ where the temperature dependence of diffusion $(D)$ due to the defect activation energy $\left(E_{a}\right)$ is described by an Arrhenius relation:

$$
D=D_{0} e^{(-\mathrm{Ea} / \mathrm{kbT})}
$$

where $D_{0}, K_{B}$ and $T$ are the diffusion pre-exponential factor, Boltzmann constant, and absolute temperature, respectively. 
To illustrate the magnitude of $D$ in alloys, the lower panel of Figure $5 \mathrm{~b}$ plots $D$ for a number of Fe-Ni diffusion couples at various temperatures using standard reference values for $E_{a}$ (see Table S1, S5-S12). For example, as illustrated in this plot Ni self-diffusion rates are the slowest, indicating a higher $E_{a}(\mathrm{Ni} \mid \mathrm{Ni})$, whereas Fe self-diffusion $(\mathrm{Fe} \mid \mathrm{Fe})$ is faster. Importantly, in the case of impurity diffusion such as nickel-in-iron ( $\mathrm{Ni} \mid \mathrm{Fe})$ or iron-in-nickel ( $\mathrm{Fe} \mid \mathrm{Ni})$, the impurity diffuses faster than the host metal. That is to say, nickel diffuses faster in iron, and iron diffuses faster in nickel.

At nanoscale interfaces, grains, and defect sites, $D$ is significantly enhanced. Consider that, for example, the measured diffusion rate of $\mathrm{Bi}$ in $\mathrm{Bi}_{2} \mathrm{O}_{3}$ nanoparticles is reported to be nearly 3 orders of magnitude faster than in bulk. ${ }^{48} \mathrm{~A}$ recent advance in understanding this involves factoring in grain boundary (GB) diffusion as a high diffusivity path at the surface, which for nanomaterials, is significant. ${ }^{24}$ For instance, considering that each NP itself is a grain, and in this system the initial Ni shell can be multigrain or a submonolayer (Scheme 1), then GB diffusion can be a dominant contributor to alloying. The $E_{a}$ relationship between grain boundary diffusion $\left(E_{\mathrm{GB}}\right)$ and bulk diffusion $\left(E_{\mathrm{B}}\right)$ have been shown to be related by; $E_{\mathrm{GB}}=0.4-0.6\left(E_{\mathrm{B}}\right) .{ }^{24}$ The top panel of Figure $5 \mathrm{~b}$ plots the calculated grain boundary diffusion coefficients of $\mathrm{Fe}$ and $\mathrm{Ni}$ (using $E_{\mathrm{gb}}=0.5 E_{B}$ ). As can be seen in the plot, there is an enhancement of many orders of magnitude than in the corresponding bulk values. While we do not expect these $D_{g b}$ values to be the true overall $D$ for alloying, they could factor in considerably at the interface between the Fe-rich core and the Ni-rich shell in our system, as has been shown for other NP alloys which show almost spontaneous alloying, ${ }^{29,49}$ as well as potentially describe rapid atomic motion in immiscible interfaces, such as in bimetallic dumbbells or asymmetric nanoparticles. ${ }^{50}$ 
In addition to enhanced diffusion, the NP interface is governed by a considerably different thermodynamic landscape as compared to bulk metals or thin films, as illustrated by the melting point depression of metal nanoparticles, which is the consequence of high interfacial energies and strain. ${ }^{28,30,31,46,51}$ For instance, the melting temperature of NPs scales with size for particles, ${ }^{29}$ and a general lowering of the phase boundaries is expected ${ }^{52-57}$ so that, for example, in this system, that the $\gamma$-FeNi phase is reached at lower temperatures.

To further address the driving force for alloying in our system, we calculated alloy mixing enthalpy $\left(\Delta H^{M i x}\right)$ and segregation enthalpy $\left(\Delta H^{S e g}\right)$ for FeNi using the scalable macroscopic atom approach, or Miedema model. ${ }^{58-60}$ In this approach, the alloy is divided into cells of dissimilar atoms and the energy perturbations (electronic, steric, and structural) are assessed to determine $\Delta H^{M i x}$. This model has been successful at describing bulk alloying and provides $\Delta H^{M i x}$ for a wide variety of compounds. ${ }^{61}$ Moreover, an assessment of $\Delta H^{M i x}$ in nanocrystalline materials has recently been used for predicting grain boundary growth in nanocrystalline solids, ${ }^{62}$ and can be defined as: ${ }^{61}$

$\Delta H^{\text {mix }}=\left[c_{\mathrm{A}} c_{\mathrm{B}}\left(c_{\mathrm{B}}^{\mathrm{s}} \Delta H_{\mathrm{AinB}}^{\text {int }}+c_{\mathrm{A}}^{\mathrm{s}} \Delta H_{\mathrm{BinA}}^{\text {int }}\right]_{\text {chemical }}+\left[c_{\mathrm{A}} c_{\mathrm{B}}\left(c_{\mathrm{B}} \Delta H_{\mathrm{AinB}}^{\text {elastic }}+c_{\mathrm{A}} \Delta H_{\mathrm{BinA}}^{\text {elastic }}\right]_{\text {elastic }}+\Delta H^{\text {structural }}\right.\right.$

where $c_{\mathrm{A}}$ and $c_{\mathrm{B}}$ are the composition of the solute and solvent, $c_{\mathrm{B}}{ }^{\mathrm{S}}$ is the fraction of the surface of $\mathrm{B}$ atoms in contact with $\mathrm{A}$ (with $c_{\mathrm{A}} \mathrm{s}$ being the fraction of $\mathrm{A}$ atoms in contact with $\mathrm{B}$ atoms) $\Delta H^{\text {int }}$ is the chemical interactions associated with surrounding $\mathrm{A}$ with $\mathrm{B}$ atoms (B with $\mathrm{A}$ ), $\Delta H^{\text {elastic }}$ describes the elastic strain of surrounding A with $\mathrm{B}$ (B with $\mathrm{A}$ ), and $\Delta H^{\text {structural }}$ describes the energy associated with crystal structure. Note that each of these values has been tabulated ${ }^{60}$ as well as $\Delta H_{M i x}$ for many binary mixtures. ${ }^{61}$ Using this approach, we calculated a $\Delta H^{M i x}$ of $-4.8 \mathrm{~kJ} / \mathrm{mol}$, which suggests favorable alloying (Table 1), as a number of researchers have shown that as $\Delta H^{M i x}$ 
values become more endothermic that better alloying is predicted and is typically enhanced by decreasing NP size. ${ }^{25-27}$ One reason for this is the lower unfavorable chemical bonding and strain interactions (i.e., reducing $\Delta H^{\mathrm{Int}}$ and $\Delta H^{\text {Elastic }}$ ) by localization at the under-coordinated NP surface. $^{29}$

Table 1: Calculated $\mathrm{D}_{\mathrm{FeNi}}, \Delta H^{M i x} \mathrm{Fe} / \mathrm{Ni}$ and $\Delta H^{\mathrm{Seg}} \mathrm{Fe} / \mathrm{Ni}$

\begin{tabular}{|c|c|c|c|c|}
\hline 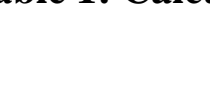 & $\begin{array}{c}D_{\mathbf{B}}\left(\mathbf{3 0 0}^{\circ} \mathbf{C}\right)^{\mathbf{1}} \\
\left(\mathrm{nm}^{2} / \mathrm{sec}\right)\end{array}$ & $\begin{array}{c}\boldsymbol{D}_{\mathbf{G B}}\left(\mathbf{3 0 0}{ }^{\mathbf{o}} \mathbf{C}\right)^{\mathbf{2}} \\
\left(\mathrm{nm}^{2} / \mathrm{sec}\right)\end{array}$ & $\begin{array}{c}\Delta \boldsymbol{H}^{\boldsymbol{M i x}} \mathrm{Fe} / \mathbf{N i}^{3} \\
(\mathrm{~kJ} / \mathrm{mol})\end{array}$ & $\begin{array}{c}\Delta H^{S e g}{ }_{\mathrm{Fe} / \mathrm{Ni}}{ }^{4} \\
(\mathrm{~kJ} / \mathrm{mol})\end{array}$ \\
\hline $\mathrm{Fe} / \mathrm{Fe}_{1-\mathrm{x}} \mathrm{Ni}_{\mathrm{x}}$ & $1.3 \times 10^{-8}$ & $1.3 \times 10^{1}$ & -4.8 & -3.4 \\
\hline
\end{tabular}

In addition to the favorable $\Delta H^{M i x}$, alloying is also driven at the nanoscale by the tendency to minimize interfacial energies, both at the core-shell or core-alloy interface, as well as between NPs and the local environment. ${ }^{49}$ The additional core-shell interfacial energy arises due to the strain developed as the shell adjusts to match the underlying core lattice structure, ${ }^{63}$ which can lead to defects and stacking faults. ${ }^{64}$ Alloying can alleviate this strain for exothermic values of $\Delta H^{M i x}$, but when $\Delta H^{M i x}$ is endothermic the enhanced diffusion can lead to coalescence or phase segregation to a dominant core-shell morphology, or asymmetric ones, like dumbbells. ${ }^{50,65}$ Similarly, minimization of the free energy at the surface can also drive alloying or enhance segregation, which is related to large differences in elemental surface $(\gamma)$ and cohesive energies $\left(E_{c}\right)$ (see SI). ${ }^{29,31,46,52,66}$

For dilute alloys, the Miedema model also allows for the prediction of whether or not a metal will segregate to the surface of an alloy $\left(\Delta H^{\mathrm{seg}}\right)$, which has been applied to grain boundary segregation by Shuh and co-workers by: ${ }^{61}$ 


$$
\Delta H^{\mathrm{seg}}=0.71 \times \frac{1}{3} \times v \times\left[-\Delta H_{\mathrm{BinA}}^{\mathrm{int}}-c_{0} \gamma_{A}^{S} V_{A}^{2 / 3}+c_{0} \gamma_{B}^{S} V_{B}^{2 / 3}\right]+\Delta E_{e l}
$$

where $v$ is a term describing the interfacial bonds between core and shell, $c_{0}$ is a constant, $\gamma$ is the surface energy of the pure metal, $V$ is the atomic volume, and $\Delta E_{e l}$ describes the energy gained from elastic strain relief, all of which are critical for understanding nanoscale segregation. Using this approach we calculated a $\Delta H^{\text {seg }}$ of $-3.4 \mathrm{~kJ} / \mathrm{mol}$ (Table 1 ) for FeNi, a value that implies only a weak preference of $\mathrm{Ni}$ on the NP surface, suggesting that segregation to the interface is not a significant barrier to alloying, again as demonstrated by the measurements and observations.
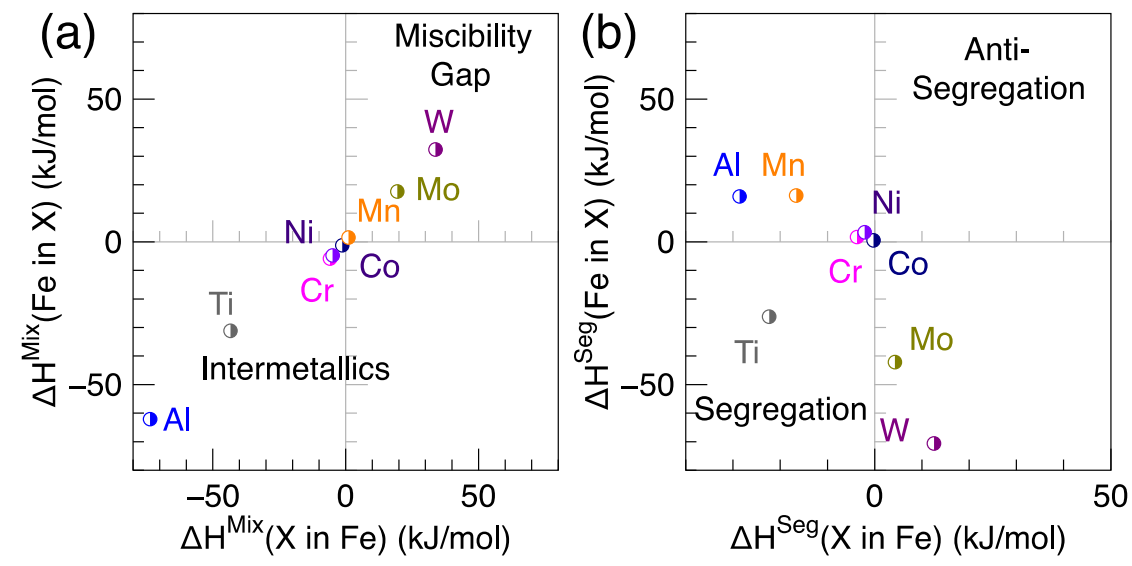

Figure 6. Plots of the mixing enthalpies, $\Delta H^{\text {Mix }}$ (a) and segregation enthalpies, $\Delta H^{\text {seg }}$ (b) for Fe-X binary couples as a function of $\mathrm{X}$ in Fe solvent and $\mathrm{Fe}$ in $\mathrm{X}$ solvent.

This study focuses on a $\mathrm{Fe} / \mathrm{Fe}_{1-\mathrm{x}} \mathrm{Ni}_{\mathrm{x}}$ core/alloy NP system, but these calculations provide a good indicator of alloying for other compositions as well. For instance, Fe-X couples are particularly interesting because many of the alloys are precursors or components of steel and other highly important structural or magnetic materials. Figure 6 shows a series of calculations of $\Delta H^{M i x}$ (a) and $\Delta H^{\text {Seg }}$ (b) for binary alloys of Fe. Those alloys close to the origin of the plots are those most 
likely to alloy. For example, the endothermic $\Delta H^{M i x}$ values for Fe-Mo and Fe-W suggest no significant alloying is expected, while systems with slightly exothermic values favor random solid solutions, like in $\mathrm{FeCr}, \mathrm{FeNi}$, and systems with highly exothermic $\Delta H^{M i x}$, like $\mathrm{Fe}-\mathrm{Al}$ and $\mathrm{Fe}-\mathrm{Ti}$ suggest highly ordered alloys in the form of intermetallics, in agreement with the bulk phase diagrams. For $\Delta H^{\text {Seg }}$, the binary $\mathrm{Fe}-\mathrm{Cr}, \mathrm{Fe}-\mathrm{Ni}$, and $\mathrm{Fe}-\mathrm{Mo}$ values are quite similar suggesting only a weak segregation to the surface, where in contrast, Fe-Al, Fe-Mo, and Fe-W all have significant segregation preferences, which may inhibit alloying. For more information on these calculations and the tabulated data used in the calculations, please see the SI.

Taken together, these results indicate how it is possible to start with a Fe/Fe ${ }_{1-x} \mathrm{Ni}_{\mathrm{x}}$ metallic nanoparticle with a thin Ni-rich shell, and form internal or gradient $\mathrm{Fe}_{1-\mathrm{x}} \mathrm{Ni}_{\mathrm{x}}$ alloys by annealing at temperatures accessible to wet-chemical, synthetic inorganic approaches. It's likely that these core/alloy NPs form core/gradient compositions post annealing, as the alloying is initiated and most concentrated at the interface, yet, further tuning of the alloy composition is achieved by longer annealing times or temperature ramp cycling. The alloying observed at these temperatures were consistent with the grain boundary enhanced diffusion constant calculations, as well as the calculations of $\Delta \mathrm{H}^{\text {mix }}$ and $\Delta \mathrm{H}^{\text {seg }}$ via the scalable-model approximation. These favorable alloying conditions and criteria, as well as the thin Ni-rich interface is likely the reason why no observable phase precipitation or heterostructures were formed, as has been shown by other researchers when Fe content is increased beyond $70 \%,{ }^{67-69}$ which is similar to observations in bulk Fe-Ni alloys, ${ }^{70}$ and Monte Carlo simulations. ${ }^{71}$ 


\section{CONCLUSIONS}

In this study we investigated the alloying of a $\mathrm{Fe}_{1-\mathrm{x}} \mathrm{Ni}_{\mathrm{x}}$ nanoparticle having a crystalline $\alpha-$ Fe core and a $\gamma$-Ni-rich shell at temperatures of $180-325^{\circ} \mathrm{C}$. The alloy nature of the NP product was investigated by XRD and XPS, and the results were examined in light of the Miedema model calculations, which were combined with grain boundary diffusion. The XRD results showed a consistent lattice constant shift with annealing temperature consistent with an increasing Ni-rich alloy. Analysis of the particle diameter both by Scherrer analysis and TEM showed a slight decrease in particle size. The XPS results showed an decreasing Fe:Ni concentration ratio as a result of annealing, which is consistent with the model of core-rich Fe atoms diffusing to the shell, and the shell rich $\mathrm{Ni}$ atoms diffusing within. The results indicate that well-formed alloys do form at the interface, and that composition and phase can be tuned by further annealing. The study focused on a simple Fe-Ni binary system, but the calculations of grain boundary diffusion values, as well as $\Delta \mathrm{H}^{\mathrm{mix}}$ and $\Delta \mathrm{H}^{\text {seg }}$ values for a number of other Fe-X systems will prove useful for guiding future work related to the synthesis of nano-steels, which is part of our ongoing work.

\section{ASSOCIATED CONTENT}

Supporting information related to modeling descriptions. Supporting Tables S1-S10 documenting the reference values used in calculations and results. Supporting Figures S1-S2 showing XRD results for a control study and additional diffusion calculations.

\section{AUTHOR INFORMATION}

\section{Corresponding Author}

*mmmaye@syr.edu

\section{Notes}


M.M.M. is a co-founder of Pelitex Inc.

\section{ACKNOWLEDGMENT}

We thank the National Science Foundation Division of Materials Research (NSF, DMR-1410569) for supporting this work. This work made use of the Cornell Center for Materials Research Shared Facilities which are supported through the NSF MRSEC program (DMR-1719875). We acknowledge additional support via a NSF MRI grant (DBI-1531757), and M.M.M. acknowledges support of a Syracuse University College of Arts \& Sciences Deans Professor of Science fellowship during the time period of the studies. 


\section{REFERENCES}

(1) Buck, M. R.; Schaak, R. E. Emerging Strategies for the Total Synthesis of Inorganic Nanostructures. Angew. Chem. Int. Ed. 2013, 52 (24), 6154-6178.

(2) Wu, W.; Maye, M. M. Void Coalescence in Core/Alloy Nanoparticles with Stainless Interfaces. Small 2014, 10 (2), 271-276.

(3) Nickel, Cobalt, and Their Alloys; Davis, J. R., Ed.; ASM specialty handbook; ASM International: Materials Park, $\mathrm{OH}, 2000$.

(4) Alloy Physics: A Comprehensive Reference; Pfeiler, W., Ed.; Wiley-VCH: Weinheim, 2007.

(5) Cui, B. Z.; Marinescu, M.; Liu, J. F. High Magnetization Fe-Co and Fe-Ni Submicron and Nanosize Particles by Thermal Decomposition and Hydrogen Reduction. J. Appl. Phys. 2014, 115 (17), 17A315.

(6) Liu, Y.; Chi, Y.; Shan, S.; Yin, J.; Luo, J.; Zhong, C.-J. Characterization of Magnetic NiFe Nanoparticles with Controlled Bimetallic Composition. J. Alloys Compd. 2014, 587, 260266.

(7) Kurlyandskaya, G. V.; Bhagat, S. M.; Bagazeev, A. V.; Medvedev, A. I.; Ballesteros, A.; Beketov, I. V.; Safronov, A. P. Structure, Magnetic and Microwave Properties of FeNi Invar Nanoparticles Obtained by Electrical Explosion of Wire in Different Preparation Conditions. J. Phys. Chem. Solids 2016, 98, 255-262.

(8) Grobert, N.; Mayne, M.; Walton, D. R. M.; Kroto, H. W.; Terrones, M.; Kamalakaran, R.; Seeger, T.; Rühle, M.; Terrones, H.; Sloan, J.; et al. Alloy Nanowires: Invar inside Carbon Nanotubes. Chem. Commun. 2001, No. 5, 471-472.

(9) Wen, F.; Zhang, F.; Xiang, J.; Hu, W.; Yuan, S.; Liu, Z. Microwave Absorption Properties of Multiwalled Carbon Nanotube/FeNi Nanopowders as Light-Weight Microwave Absorbers. J. Magn. Magn. Mater. 2013, 343, 281-285.

(10) Liu, X. G.; Ou, Z. Q.; Geng, D. Y.; Han, Z.; Jiang, J. J.; Liu, W.; Zhang, Z. D. Influence of a Graphite Shell on the Thermal and Electromagnetic Characteristics of FeNi Nanoparticles. Carbon 2010, 48 (3), 891-897.

(11) Gilroy, K. D.; Ruditskiy, A.; Peng, H.-C.; Qin, D.; Xia, Y. Bimetallic Nanocrystals: Syntheses, Properties, and Applications. Chem. Rev. 2016, 116 (18), 10414-10472.

(12) Li, J.; Tang, W.; Yang, H.; Dong, Z.; Huang, J.; Li, S.; Wang, J.; Jin, J.; Ma, J. EnhancedElectrocatalytic Activity of $\mathrm{Ni}_{1-\mathrm{x}} \mathrm{Fe} x$ Alloy Supported on Polyethyleneimine Functionalized $\mathrm{MoS}_{2}$ Nanosheets for Hydrazine Oxidation. RSC Adv 2014, 4 (4), 19881995.

(13) Yang, H.; Zhong, X.; Dong, Z.; Wang, J.; Jin, J.; Ma, J. A Highly Active Hydrazine Fuel Cell Catalyst Consisting of a Ni-Fe Nanoparticle Alloy Plated on Carbon Materials by Pulse Reversal. RSC Adv. 2012, 2 (12), 5038.

(14) McNamara, K.; Tofail, S. A. M. Nanosystems: The Use of Nanoalloys, Metallic, Bimetallic, and Magnetic Nanoparticles in Biomedical Applications. Phys Chem Chem Phys 2015, 17 (42), 27981-27995.

(15) Kannan, P.; Maiyalagan, T.; Marsili, E.; Ghosh, S.; Niedziolka-Jönsson, J.; JönssonNiedziolka, M. Hierarchical 3-Dimensional Nickel-iron Nanosheet Arrays on Carbon Fiber Paper as a Novel Electrode for Non-Enzymatic Glucose Sensing. Nanoscale 2016, 8 (2), 843-855. 
(16) Teeriniemi, J.; Melander, M.; Lipasti, S.; Hatz, R.; Laasonen, K. Fe-Ni Nanoparticles: A Multiscale First-Principles Study to Predict Geometry, Structure, and Catalytic Activity. J. Phys. Chem. C 2017, 121 (3), 1667-1674.

(17) Berlia, R.; Kumar MK, P.; Srivastava, C. Synthesis and Electrochemical Behaviour of NiFeCr Nanoparticle Coatings. RSC Adv. 2015, 5 (39), 30877-30881.

(18) Ban, I.; Drofenik, M.; Makovec, D. The Synthesis of Iron-nickel Alloy Nanoparticles Using a Reverse Micelle Technique. J. Magn. Magn. Mater. 2006, 307 (2), 250-256.

(19) Gurmen, S.; Ebin, B.; Stopić, S.; Friedrich, B. Nanocrystalline Spherical Iron-nickel (FeNi) Alloy Particles Prepared by Ultrasonic Spray Pyrolysis and Hydrogen Reduction (USP-HR). J. Alloys Compd. 2009, 480 (2), 529-533.

(20) Pavithra, G. P.; Hegde, A. C. Magnetic Property and Corrosion Resistance of Electrodeposited Nanocrystalline Iron-nickel Alloys. Appl. Surf. Sci. 2012, 258 (18), 6884-6890.

(21) Qazi, U. Y.; Yuan, C.-Z.; Ullah, N.; Jiang, Y.-F.; Imran, M.; Zeb, A.; Zhao, S.-J.; Javaid, R.; Xu, A.-W. One-Step Growth of Iron-Nickel Bimetallic Nanoparticles on FeNi Alloy Foils: Highly Efficient Advanced Electrodes for the Oxygen Evolution Reaction. ACS Appl. Mater. Interfaces 2017, 9 (34), 28627-28634.

(22) Jing, P.; Liu, M.; Pu, Y.; Cui, Y.; Wang, Z.; Wang, J.; Liu, Q. Dependence of Phase Configurations, Microstructures and Magnetic Properties of Iron-Nickel (Fe-Ni) Alloy Nanoribbons on Deoxidization Temperature in Hydrogen. Sci. Rep. 2016, 6 (1).

(23) Seol, J.-B.; Na, S.-H.; Gault, B.; Kim, J.-E.; Han, J.-C.; Park, C.-G.; Raabe, D. Core-Shell Nanoparticle Arrays Double the Strength of Steel. Sci. Rep. 2017, 7, 42547.

(24) Mehrer, H. Diffusion in Solids Fundamentals, Methods, Materials, Diffusion-Controlled Processes; Springer: Berlin; New York, 2007.

(25) Xiao, S.; Hu, W.; Luo, W.; Wu, Y.; Li, X.; Deng, H. Size Effect on Alloying Ability and Phase Stability of Immiscible Bimetallic Nanoparticles. Eur. Phys. J. B 2006, 54 (4), 479484.

(26) Martinez De La Hoz, J. M.; Callejas Tovar, R.; Balbuena, P. B. Size Effect on the Stability of Cu-Ag Nanoalloys. Mol. Simul. 2009, 35 (10-11), 785-794.

(27) Xiong, S.; Qi, W.; Huang, B.; Wang, M. Size-, Shape- and Composition-Dependent Alloying Ability of Bimetallic Nanoparticles. ChemPhysChem 2011, 12 (7), 1317-1324.

(28) Marks, L. D.; Peng, L. Nanoparticle Shape, Thermodynamics and Kinetics. J. Phys. Condens. Matter 2016, 28 (5), 53001.

(29) Ferrando, R. Frontiers of Nanoscience Structure and Properties of Nanoalloys.; Elsevier Science, 2016.

(30) Calvo, F. Thermodynamics of Nanoalloys. Phys Chem Chem Phys 2015, 17 (42), 2792227939.

(31) Peng, L.; Ringe, E.; Van Duyne, R. P.; Marks, L. D. Segregation in Bimetallic Nanoparticles. Phys Chem Chem Phys 2015, 17 (42), 27940-27951.

(32) Pathade, L.; Doane, T. L.; Slaton, R. D.; Maye, M. M. Understanding the Oxidation Behavior of $\mathrm{Fe} / \mathrm{Ni} / \mathrm{Cr}$ and $\mathrm{Fe} / \mathrm{Cr} / \mathrm{Ni}$ Core/Alloy Nanoparticles. J. Phys. Chem. C 2016, 120 (38), 22035-22044.

(33) Wu, W.; Njoki, P. N.; Han, H.; Zhao, H.; Schiff, E. A.; Lutz, P. S.; Solomon, L.; Matthews, S.; Maye, M. M. Processing Core/Alloy/Shell Nanoparticles: Tunable Optical Properties and Evidence for Self-Limiting Alloy Growth. J. Phys. Chem. C 2011, 115 (20), 9933-9942. 
(34) Slaton, R. D.; Bae, I.-T.; Lutz, P. S.; Pathade, L.; Maye, M. M. The Transformation of $\alpha-$ Fe Nanoparticles into Multi-Domain $\mathrm{FeNi}-\mathrm{M}_{3} \mathrm{O}_{4}(\mathrm{M}=\mathrm{Fe}, \mathrm{Ni})$ Heterostructures by Galvanic Exchange. J Mater Chem C 2015, 3 (24), 6367-6375.

(35) Wu, H.-Q.; Wei, X.-W.; Shao, M.-W.; Gu, J.-S.; Qu, M.-Z. Preparation of Fe-Ni Alloy Nanoparticles inside Carbon Nanotubes via Wet Chemistry. J. Mater. Chem. 2002, 12 (6), 1919-1921.

(36) Suh, Y. J.; Jang, H. D.; Chang, H.; Kim, W. B.; Kim, H. C. Size-Controlled Synthesis of Fe-Ni Alloy Nanoparticles by Hydrogen Reduction of Metal Chlorides. Powder Technol. 2006, 161 (3), 196-201.

(37) Bai, S.; Shen, X.; Zhu, G.; Xu, Z.; Yang, J. In Situgrowth of FeNi Alloy Nanoflowers on Reduced Graphene Oxide Nanosheets and Their Magnetic Properties. CrystEngComm 2012, 14 (4), 1432-1438.

(38) Moghimi, N.; Bazargan, S.; Pradhan, D.; Leung, K. T. Phase-Induced Shape Evolution of FeNi Nanoalloys and Their Air Stability by in-Situ Surface Passivation. J. Phys. Chem. C 2013, 117 (9), 4852-4858.

(39) Moghimi, N.; Abdellah, M.; Thomas, J. P.; Mohapatra, M.; Leung, K. T. Bimetallic FeNi Concave Nanocubes and Nanocages. J. Am. Chem. Soc. 2013, 135 (30), 10958-10961.

(40) Chen, M.; Liu, J. P.; Sun, S. One-Step Synthesis of FePt Nanoparticles with Tunable Size. J. Am. Chem. Soc. 2004, 126 (27), 8394-8395.

(41) Desvaux, C.; Amiens, C.; Fejes, P.; Renaud, P.; Respaud, M.; Lecante, P.; Snoeck, E.; Chaudret, B. Multimillimetre-Large Superlattices of Air-Stable Iron-cobalt Nanoparticles. Nat. Mater. 2005, 4 (10), 750-753.

(42) Peng, S.; Wang, C.; Xie, J.; Sun, S. Synthesis and Stabilization of Monodisperse Fe Nanoparticles. J. Am. Chem. Soc. 2006, 128 (33), 10676-10677.

(43) Lacroix, L.-M.; Frey Huls, N.; Ho, D.; Sun, X.; Cheng, K.; Sun, S. Stable SingleCrystalline Body Centered Cubic Fe Nanoparticles. Nano Lett. 2011, 11 (4), 1641-1645.

(44) Wojdyr, M. Fityk: A General-Purpose Peak Fitting Program. J. Appl. Crystallogr. 2010, 43 (5), 1126-1128.

(45) Silman, G. I. Compilative Fe - Ni Phase Diagram with Author's Correction. Met. Sci. Heat Treat. 2012, 54 (3-4), 105-112.

(46) Ferrando, R.; Jellinek, J.; Johnston, R. L. Nanoalloys: From Theory to Applications of Alloy Clusters and Nanoparticles. Chem. Rev. 2008, 108 (3), 845-910.

(47) Bokshteĭn, B. S.; Bokshteǐn, S. Z.; Zhukhovitski1, A. A. Thermodynamics and Kinetics of Diffusion in Solids; Oxonian Press: New Delhi, 1985.

(48) Niu, K.-Y.; Park, J.; Zheng, H.; Alivisatos, A. P. Revealing Bismuth Oxide Hollow Nanoparticle Formation by the Kirkendall Effect. Nano Lett. 2013, 13 (11), 5715-5719.

(49) Ouyang, G.; Tan, X.; Wang, C. X.; Yang, G. W. Physical and Chemical Origin of SizeDependent Spontaneous Interfacial Alloying of Core-shell Nanostructures. Chem. Phys. Lett. 2006, 420 (1-3), 65-70.

(50) Njoki, P. N.; Lutz, P.; Wu, W.; Solomon, L.; Maye, M. M. Exploiting Core-shell and Core-alloy Interfaces for Asymmetric Growth of Nanoparticles. Chem. Commun. 2012, 48 (84), 10449.

(51) Ringe, E.; Van Duyne, R. P.; Marks, L. D. Wulff Construction for Alloy Nanoparticles. Nano Lett. 2011, 11 (8), 3399-3403.

(52) Guisbiers, G.; Mendoza-Cruz, R.; Bazán-Díaz, L.; Velázquez-Salazar, J. J.; MendozaPerez, R.; Robledo-Torres, J. A.; Rodriguez-Lopez, J.-L.; Montejano-Carrizales, J. M.; 
Whetten, R. L.; José-Yacamán, M. Electrum, the Gold-Silver Alloy, from the Bulk Scale to the Nanoscale: Synthesis, Properties, and Segregation Rules. ACS Nano 2016, 10 (1), 188-198.

(53) Qi, W. Nanoscopic Thermodynamics. Acc. Chem. Res. 2016, 49 (9), 1587-1595.

(54) Bajaj, S.; Haverty, M. G.; Arróyave, R.; Goddard III FRSC, W. A.; Shankar, S. Phase Stability in Nanoscale Material Systems: Extension from Bulk Phase Diagrams. Nanoscale 2015, 7 (21), 9868-9877.

(55) Guisbiers, G.; Mejia-Rosales, S.; Khanal, S.; Ruiz-Zepeda, F.; Whetten, R. L.; JoséYacaman, M. Gold-Copper Nano-Alloy, "Tumbaga”, in the Era of Nano: Phase Diagram and Segregation. Nano Lett. 2014, 14 (11), 6718-6726.

(56) Qi, W. H.; Wang, M. P. Size and Shape Dependent Melting Temperature of Metallic Nanoparticles. Mater. Chem. Phys. 2004, 88 (2-3), 280-284.

(57) Wautelet, M.; Dauchot, J. P.; Hecq, M. Phase Diagrams of Small Particles of Binary Systems: A Theoretical Approach. Nanotechnology 2000, 11 (1), 6-9.

(58) Miedema, A. .; Boom, R.; De Boer, F. . On the Heat of Formation of Solid Alloys. J. Common Met. 1975, 41 (2), 283-298.

(59) Miedema, A. R.; de Châtel, P. F.; de Boer, F. R. Cohesion in Alloys - Fundamentals of a Semi-Empirical Model. Phys. BC 1980, 100 (1), 1-28.

(60) Cohesion in Metals: Transition Metal Alloys, 2., print.; Boer, F. R. de, Ed.; Cohesion and structure; North Holland: Amsterdam, 1988.

(61) Murdoch, H. A.; Schuh, C. A. Estimation of Grain Boundary Segregation Enthalpy and Its Role in Stable Nanocrystalline Alloy Design. J. Mater. Res. 2013, 28 (16), 2154-2163.

(62) Chookajorn, T.; Murdoch, H. A.; Schuh, C. A. Design of Stable Nanocrystalline Alloys. Science 2012, 337 (6097), 951-954.

(63) Strasser, P.; Koh, S.; Anniyev, T.; Greeley, J.; More, K.; Yu, C.; Liu, Z.; Kaya, S.; Nordlund, D.; Ogasawara, H.; et al. Lattice-Strain Control of the Activity in Dealloyed Core-shell Fuel Cell Catalysts. Nat. Chem. 2010, 2 (6), 454-460.

(64) Bhattarai, N.; Casillas, G.; Ponce, A.; Jose-Yacaman, M. Strain-Release Mechanisms in Bimetallic Core-shell Nanoparticles as Revealed by Cs-Corrected STEM. Surf. Sci. 2013, 609, 161-166.

(65) Wen, T.; Krishnan, K. M. Thermal Stability and Morphological Transformations of Au Core -Co Shell Nanocrucibles. J. Phys. Chem. C 2010, 114 (35), 14838-14842.

(66) Wang, L.-L.; Johnson, D. D. Predicted Trends of Core-Shell Preferences for 132 Late Transition-Metal Binary-Alloy Nanoparticles. J. Am. Chem. Soc. 2009, 131 (39), 1402314029.

(67) Li, X. G.; Chiba, A.; Takahashi, S. Preparation and Magnetic Properties of Ultrafine Particles of Fe $\square$ Ni Alloys. J. Magn. Magn. Mater. 1997, 170 (3), 339-345.

(68) Wu, H.-Q.; Cao, Y.-J.; Yuan, P.-S.; Xu, H.-Y.; Wei, X.-W. Controlled Synthesis, Structure and Magnetic Properties of Fe1-xNix Alloy Nanoparticles Attached on Carbon Nanotubes. Chem. Phys. Lett. 2005, 406 (1-3), 148-153.

(69) Glaubitz, B.; Buschhorn, S.; Brüssing, F.; Abrudan, R.; Zabel, H. Development of Magnetic Moments in Fe ${ }_{1-X} \mathrm{Ni}_{X}$-Alloys. J. Phys. Condens. Matter 2011, 23 (25), 254210.

(70) McKeehan, L. The Crystal Structure of Iron-Nickel Alloys. Phys. Rev. 1923, 21 (4), 402407. 
(71) Byshkin, M.; Hou, M. Phase Transformations and Segregation in Fe-Ni Alloys and Nanoalloys. J. Mater. Sci. 2012, 47 (15), 5784-5793.

\section{TOC Graphic}

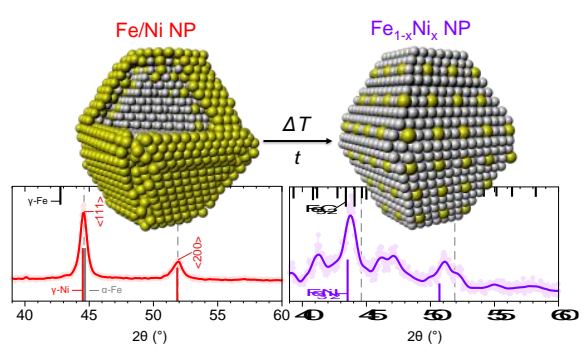

